\title{
Aplicação da modularidade na indústria automobilística: análise a partir de um levantamento tipo survey
}

\author{
José Antonio Carnevalli ${ }^{*}$, Paulo Augusto Cauchick Miguel ${ }^{\mathrm{b}}$, Mario Sergio Salerno \\ a*jcarnevalli@hotmail.com, POLl-USP, Brasil \\ bcauchick@usp.br, POLl-USP, Brasil \\ 'msalerno@usp.br, POLl-USP, Brasil
}

\begin{abstract}
Resumo
Esta investigação tem como objetivo identificar empresas do setor automobilístico que utilizam a estratégia modular e analisar aspectos do seu uso. Para tanto, foi realizado um levantamento tipo survey com o envio de um questionário para cerca de 350 empresas deste segmento, com aproximadamente 14\% de taxa de retorno. Verificou-se que a maioria das empresas tem certa experiência com a modularidade. As dificuldades para as montadoras estão principalmente na capacitação dos fornecedores. Já os fornecedores apresentam dificuldades para atender às exigências das montadoras de projetar e fabricar os módulos. Em relação aos benefícios do uso da modularidade para as montadoras, a maioria está relacionada com a terceirização de atividades para o fornecedor, tal como a transferência de custos fixos para os fornecedores. Para os fornecedores, os principais benefícios envolvem o aumento da parceria com o cliente, como ter exclusividade de fornecimento e desenvolver novas competências organizacionais.
\end{abstract}

Palavras-chaves

Modularidade. Projeto modular. Produção modular. Setor automotivo.

\section{Introdução}

A partir da década de 90 as empresas automobilísticas no Brasil têm sofrido grandes transformações e adaptações para conseguir atender um mercado consumidor mais exigente e competitivo. Essas transformações foram acentuadas com a abertura do mercado e entrada no país de novas montadoras, novas fábricas em adição às marcas já presentes no país (SALERNO, 2001; RACHID et al., 2006). Tais investimentos tiveram como característica a adoção da modularidade, tanto no projeto quanto na fabricação (MARX; ZILBOVICIUS; SALERNO, 1997; SALERNO et al., 1998, 2009; SALERNO, 2001; SCAVARDA et al., 2005; DIAS; SALERNO, 2009).

A modularidade pode ser considerada uma estratégia (MORRIS; DONNELLY, 2006), que consiste em produtos formados por módulos (subconjuntos) que trabalham juntos e podem ser projetados e fabricados de forma independente (PERSSON, 2006). Tal aplicação pode permitir a terceirização do desenvolvimento de alguns módulos (FREDRIKSSON, 2006a) e de sua montagem para os fornecedores da montadora (ORSATO; WELLS, 2007).

Entretanto, a modularidade pode gerar conflitos entre montadoras e fornecedores, pois a divisão de funções e responsabilidades entre as empresas pode ter limites, dadas as exigências financeiras colocadas para os fornecedores (MARX; ZILBOVICIUS; SALERNO, 1997; SALERNO, 2001; MORRIS; DONNELLY, 2006), as quais podem sobrecarrega-los.

No Brasil foram localizados apenas dois estudos abrangentes sobre o impacto da modularidade. 0 primeiro é um levantamento do tipo survey e estudo de casos de Salerno et al. (1998), que mapeou as novas relações na cadeia de suprimentos e discutiu questões financeiras e de localização de projeto de produto (SALERNO et al., 2009). 0 segundo trata-se de uma análise econométrica a partir de dados do IBGE (SALERNO et al., 2008), discutindo a repartição 
de margens na cadeia. Para aprofundar, atualizar as questões sobre modularidade e verificar outros aspectos relacionados ao tema foi realizada uma nova survey. Nesse sentido, o objetivo deste trabalho é apresentar e discutir os resultados de um estudo descritivo sobre o uso da modularidade em empresas montadoras e seus fornecedores, especificando quais tipos de modularidade são mais adotados e aspectos do seu uso, tais como benefícios e dificuldades na sua aplicação.

\section{Fundamentação teórica}

Em linhas gerais, a modularidade pode envolver quatro diferentes perspectivas:

- Modularidade de projeto - consiste em projetar produtos modulares definindo os módulos (subconjuntos), suas funções e interfaces, de modo que sejam independentes mas trabalhem no produto de forma interdependente (BALDWIN; CLARK, 2000; SAKO; MURRAY, 1999);

- Modularidade de produção - consiste em simplificar os processos de fabricação e de montagem definindo módulos para a produção e facilitando as configurações do produto final; podendo ou não transferir alguma dessas atividades para os fornecedores (ARNHEITER; HARREN, 2005; SAKO; MURRAY, 1999);

- Modularidade de processos organizacionais-alterações de procedimentos organizacionais e do relacionamento da empresa com seus fornecedores, para adotar a produção modular (CAMUFFO, 2000);

- Modularidade de uso - consiste na adaptação do produto final aos requisitos dos clientes (customização em massa), por alterações de módulos, que podem ser opcionais, de performance e modularidade de manutenção (PANDREMENOS et al., 2009; BALDWIN; CLARK, 2000; SAKO; MURRAY, 1999).

0 produto modular pode ajudar a personalizar produtos para o mercado local (SALERNO, 2001); reduzir tempo de projeto (VELOSO; FIXSON, 2001); aumentar a flexibilidade da produção (SALERNO, 2001; CONNOLLY, 2007). Também possibilitam reduzir os custos em gestão da cadeia de suprimentos, com a redução do número de fornecedores diretos (SALERNO et al., 1998; DORAN, 2005) e/ou reduzir a mão de obra na montadora (ARNHEITER; HARREN, 2005), entre outros.

Alguns estudos (ASAN et al., 2004; MORRIS; DONNELLY, 2006) mostram que a introdução e gestão da modularidade não é simples. Nesse sentido, esse trabalho realiza um estudo descritivo sobre o uso da modularidade em empresas montadoras e seus fornecedores para verificar se os aspectos identificados na literatura (Quadro 1) são concordantes ou discordantes com a realidade das empresas estudadas.

\section{Métodos de pesquisa}

Para atender ao objetivo do presente estudo foi realizado levantamento de campo tipo survey exploratório-descritivo (conforme a tipologia de FORZA, 2002). Segundo o autor supracitado, esse tipo de trabalho de campo avalia a amostra de uma população por meio da coleta de dados de forma individual, em geral via questionário. Além disso, o levantamento serviu para identificar empresas com experiência no uso da modularidade para investigação em maior profundidade por meio de casos múltiplos, a serem reportados futuramente.

A amostra da survey é não probabilística (não casual), ou seja, a escolha dos elementos da amostra não é aleatória (LEVIN, 1987). É uma amostra intencional, escolhida deliberadamente pelos pesquisadores, conforme a possibilidade destacada por Oliveira (1997). No presente trabalho, é formada por:

- Montadoras automotivas (automóveis, camionetes, jipes, caminhões, ônibus, tratores, máquinas agrícolas, motocicletas) associadas à Anfavea (Associação Nacional dos Fabricantes de Veículos Automotores); e

- Fornecedores (nacionais e multinacionais), parte associados ao Sindipeças (Sindicato Nacional da Indústria de Componentes para Veículos Automotores), incluindo ainda uma consulta à base de dados do CREA-SP (Conselho Regional de Engenharia, Arquitetura e Agronomia do Estado de São Paulo), totalizado 348 empresas.

Esse tipo de amostra é utilizado quando os pesquisadores não buscam generalizar os resultados para uma população, sendo uma macrofase exploratória que busca identificar empresas com experiência no uso da modularidade a serem investigadas com mais profundidade em futuros estudos (conforme estabelecido por MATTAR, 1996; MARCONI; LAKATOS, 2007).

Para a coleta de dados foi elaborado um questionário, enviado por correio, elaborado a partir da literatura (Quadro 1), considerando também dados empíricos de três estudos de casos-piloto. Para empresas multiplantas buscou-se encaminhar o questionário para cada planta, pois estas poderiam ou não aplicar a modularidade. Os questionários foram encaminhados aos gerentes da engenharia de cada empresa, sendo respondidos, na maioria dos casos, por esses gerentes. Entretanto, alguns questionários foram respondidos por ocupantes de outros cargos correlacionados, como por exemplo engenheiros (de processo, qualidade, do produto) e analistas de produto.

Como a amostra do levantamento envolve tanto empresas montadoras como fornecedores, optou-se 
Quadro 1. Principais aspectos investigados.

\begin{tabular}{|c|c|c|}
\hline \multicolumn{2}{|c|}{ Aspectos investigados } & Referências \\
\hline \multirow{4}{*}{$\begin{array}{l}\text { ldentificar os tipos de } \\
\text { modularidade adotados }\end{array}$} & Projeto & Baldwin e Clark (2000), Sako e Murray (1999) \\
\hline & & Arnheiter e Harren (2005), Sako e Murray (1999) \\
\hline & Processos organizacionais & Camuffo $(2000)$ \\
\hline & Uso & $\begin{array}{c}\text { Pandremenos et al. (2009), Baldwin e Clark (2000), Sako e } \\
\text { Murray (1999) }\end{array}$ \\
\hline \multirow{6}{*}{$\begin{array}{l}\text { Identificar os principais } \\
\text { motivos que levaram } \\
\text { a empresa a adotar a } \\
\text { abordagem modular }\end{array}$} & $\begin{array}{l}\text { Reduzir os recursos / investimentos para o } \\
\text { empreendimento }\end{array}$ & $\begin{array}{l}\text { Marx, Zilbovicius e Salerno (1997), Salerno (2001), } \\
\text { Doran et al. (2007), Arnheiter e Harren (2005) }\end{array}$ \\
\hline & Reduzir tempo de projeto & $\begin{array}{c}\text { Arnheiter e Harren (2005), Sanchez e Collins (2001), Veloso } \\
\text { e Fixson (2001) }\end{array}$ \\
\hline & Aumentar a variedade de produtos & Orsato e Wells (2007), Moeckel et al. (2006) \\
\hline & Aumentar a flexibilidade da produção & $\begin{array}{c}\text { Salerno (2001), Connolly (2007), Lau et al. (2007), } \\
\text { Fredriksson (2006b) }\end{array}$ \\
\hline & Reduzir custos de fabricação & Veloso e Fixson (2001), Gu e Sosale (1999) \\
\hline & $\begin{array}{l}\text { Para ter contratos de longos períodos com as } \\
\text { montadoras, o que diminui a concorrência }\end{array}$ & Arnheiter e Harren (2005), Pires (2002) \\
\hline \multirow{7}{*}{$\begin{array}{c}\text { Principais problemas } \\
\text { encontrados pela empresa na } \\
\text { implantação da abordagem } \\
\text { modular }\end{array}$} & $\begin{array}{l}\text { Mudar a cadeia de suprimentos tradicional } \\
\text { para a modular }\end{array}$ & Doran (2005), Hoek e Weken (1998) \\
\hline & Encontrar fornecedores capacitados & Arnheiter e Harren (2005) \\
\hline & $\begin{array}{c}\text { Aumentar o risco de a linha de montagem } \\
\text { parar se houver problemas de entrega ou de } \\
\text { qualidade }\end{array}$ & Fredriksson (2006a, c), Larsson (2002) \\
\hline & Reprojetar produto e processo & Hoek e Weken (1998) \\
\hline & Ter operações flexíveis à demanda & Fredriksson (2006a), Doran (2003) \\
\hline & Se tornar capacitado a fabricar os módulos & Arnheiter e Harren (2005), Doran (2002) \\
\hline & $\begin{array}{l}\text { Aumentar a dependência da empresa das } \\
\text { decisões das montadoras }\end{array}$ & Holmes (2004), Frigant e Lung (2002) \\
\hline \multirow{6}{*}{$\begin{array}{l}\text { Principais benefícios da } \\
\text { implantação da abordagem } \\
\text { modular }\end{array}$} & $\begin{array}{l}\text { Reduzir o tempo de desenvolvimento de } \\
\text { projeto }\end{array}$ & Arnheiter e Harren (2005), Sanchez e Collins (2001) \\
\hline & Reduzir os custos de projeto e de fabricação & Veloso e Fixson (2001) \\
\hline & Aumentar a flexibilidade da produção & Connolly (2007), Lau et al. (2007), Fredriksson (2006b) \\
\hline & $\begin{array}{l}\text { Possibilitar o envolvimento de fornecedores no } \\
\text { processo de fabricação da montadora }\end{array}$ & Frigant e Lung (2002), Hoek e Weken (1998) \\
\hline & Reduzir o número de fornecedores & $\begin{array}{c}\text { Arnheiter e Harren (2005, 2006), Cauchick Miguel e Pires } \\
\text { (2006), Doran (2005) }\end{array}$ \\
\hline & $\begin{array}{l}\text { Criar contratos de longo período entre a } \\
\text { montadora e o fornecedor }\end{array}$ & Arnheiter e Harren (2005), Pires (2002) \\
\hline
\end{tabular}

Fonte: elaborado pelos autores.

por elaborar apenas um tipo de questionário. 0 questionário foi então formado por questões que são comuns a todas as empresas e por questões que são específicas para as montadoras ou para os fornecedores.

As questões fechadas foram diretamente tabuladas em planilhas eletrônicas (MS Excel ${ }^{\circledR}$ ), usando a estatística descritiva para apresentação gráfica dos resultados. $\mathrm{Na}$ análise foi realizada a comparação dos resultados com a literatura, uma vez que as questões foram rastreadas às fontes bibliográficas, além de ter sido realizada uma análise cruzada dos resultados entre as questões. Os principais resultados são destacados a seguir.

\section{Análise dos resultados}

0 levantamento teve um índice de retorno global de 25,6\% (89 empresas), considerando os questionários devolvidos em branco (esta era uma alternativa que a empresa poderia assinalar se, por algum motivo, não pudesse respondê-lo). Considerando apenas os questionários respondidos este índice cai para uma taxa de retorno útil de 13,8\% (48 empresas). Entretanto, dos 41 questionários devolvidos em branco 7 informaram por e-mail ou carta que não adotavam a modularidade, sendo este o motivo de não terem respondido o questionário, o que eleva 0 índice de retorno útil para mais de 15\% (55 empresas). Considerando esta taxa de retorno, verifica-se que está de acordo com o praticado na literatura (em torno de 3\% a 10\% para Boyd e Wetfall (1964), sendo que para Mattar (1996), esse índice pode variar de $3 \%$ a $50 \%$ ).

Neste trabalho foram identificadas 30 empresas que utilizam a modularidade, sendo 8 montadoras e 22 fornecedores. No total, essas empresas correspondem a pouco mais de um terço dos questionários devolvidos (Figura 1). Considerando-se as 54 empresas que utilizam ou não a estratégia modular (uma empresa não 
confirmou a utilização ou não da estratégia), verifica-se que a maioria das montadoras que responderam o questionário a utilizam (8 de um total de 11), assim como pouco mais da metade dos fornecedores (22 de um total de 43) a tem utilizado. Sabe-se, no entanto, que a adoção pelos fornecedores tem influência das montadoras, conforme pode ser verificado na Figura 5.

Para verificar como a empresa define a modularidade foi considerada uma questão de múltipla escolha apresentando para as empresas as definições da literatura (anteriormente citadas): modularidade de projeto, modularidade de uso, modularidade de produção e modularidade de processos organizacionais. Esses resultados são apresentados na Figura 2. Verifica-se que as duas primeiras definições (projeto e produção) são as mais indicadas pelas empresas. Este fato não é surpreendente, visto que a modularidade de projeto foi aprimorada pela IBM (BALDWIN; CLARK, 2000) e acredita-se que os benefícios da aplicação naquele setor chamaram a atenção das montadoras de veículos, como destacam Baldwin e Clark (1997). Com relação à modularidade de produção, esta já é conhecida desde a 11 Guerra Mundial na fabricação de navios, conforme trabalho de Elphick (2006).

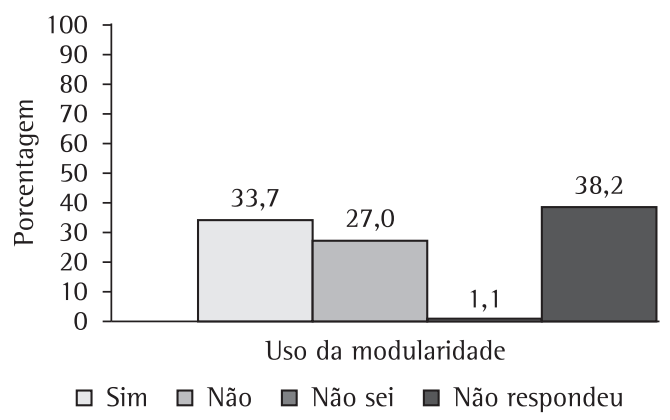

Figura 1. Adoção da modularidade ( $\mathrm{n}=55$ empresas). Fonte: elaborado pelos autores.

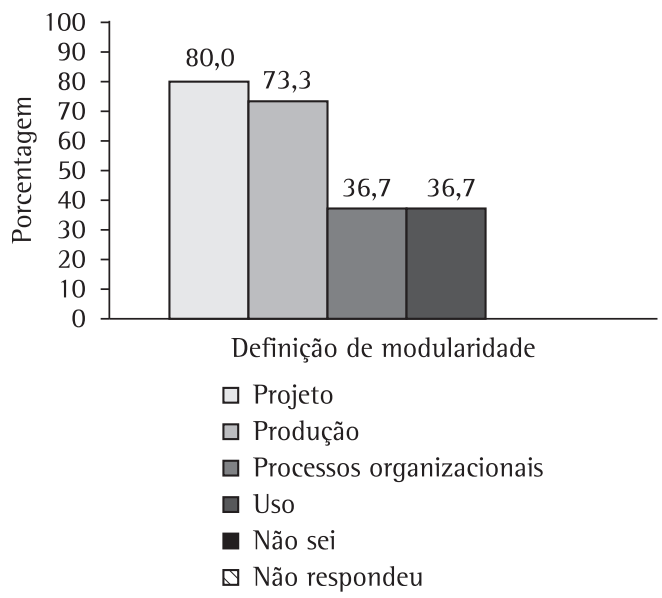

Figura 2. Definição da modularidade ( $n=30$ empresas). Fonte: elaborado pelos autores.
A Figura 3 apresenta o tipo de modularidade que as empresas realmente aplicam, podendo ser adotados somente um ou os quatro tipos em conjunto. Verifica-se que a grande maioria das empresas que respondeu o questionário utiliza a modularidade de projeto (mais de $87 \%$ das montadoras e $81 \%$ dos fornecedores) e/ou de produção (mais de $74 \%$, em ambos os casos). De certa maneira isso era esperado, pois a maioria dos benefícios da aplicação da modularidade está relacionada à aplicação desses dois tipos. Também é importante notar na Figura 3 que a modularidade de uso, que customiza o produto para o cliente, é pouco aplicada no Brasil (25\% das montadoras e menos de $41 \%$ dos fornecedores). No país, a customização do veículo de passeio está mais voltada à utilização de kits de opcionais realizada nas concessionárias (SCAVARDA et al., 2005), tornando a customização relativamente limitada. A modularidade organizacional também foi pouco citada quando comparada com a de projeto e a de produção (25\% das montadoras e 50\% dos fornecedores). Esse tipo de modularidade está relacionado à adaptação organizacional que a empresa realiza para aplicá-la e os resultados indicam que são os fornecedores que mais têm que se adaptar à modularidade (conforme estabelecido por CAMUFFO, 2000).

$\mathrm{Na}$ análise do gráfico da Figura 3 verifica-se que 13 empresas ( 5 montadoras e 8 fornecedores) utilizavam dois tipos de modularidade e 10 empresas ( 1 montadora e 9 fornecedores) aplicavam mais de dois tipos de modularidade. Verifica-se assim que, em geral, a maioria das montadoras que participaram do estudo utiliza dois tipos de modularidade (principalmente de projeto e produção), enquanto que os fornecedores têm utilizado mais de dois tipos de modularidade. Isso pode indicar que os diferentes tipos são complementares entre si, o que favoreceria o seu uso conjunto. 0 uso de mais de um tipo de modularidade na indústria automotiva do Brasil ou da Europa também foi identificado em outras publicações (SALERNO, 2001; FREDRIKSSON, 2006a, 2006c).

A Figura 4 mostra que pouco mais da metade das empresas aplica a modularidade há pelo menos 10 anos, o que pode indicar experiência na sua aplicação. Além disso, verificou-se que a maioria das aplicações ocorreu na década de 90 (15 empresas das 23 que responderam a questão, sendo que 12 delas introduziram a modularidade na segunda metade da década). É nesse período que Salerno et al. (2009) destacam o surgimento da modularidade na indústria automotiva brasileira e também foi nessa época que ocorreu uma nova fase de investimento no setor (RACHID et al., 2006), corroborando os dados da literatura.

Foi solicitado que as empresas montadoras indicassem quais foram as razões que as levaram a 


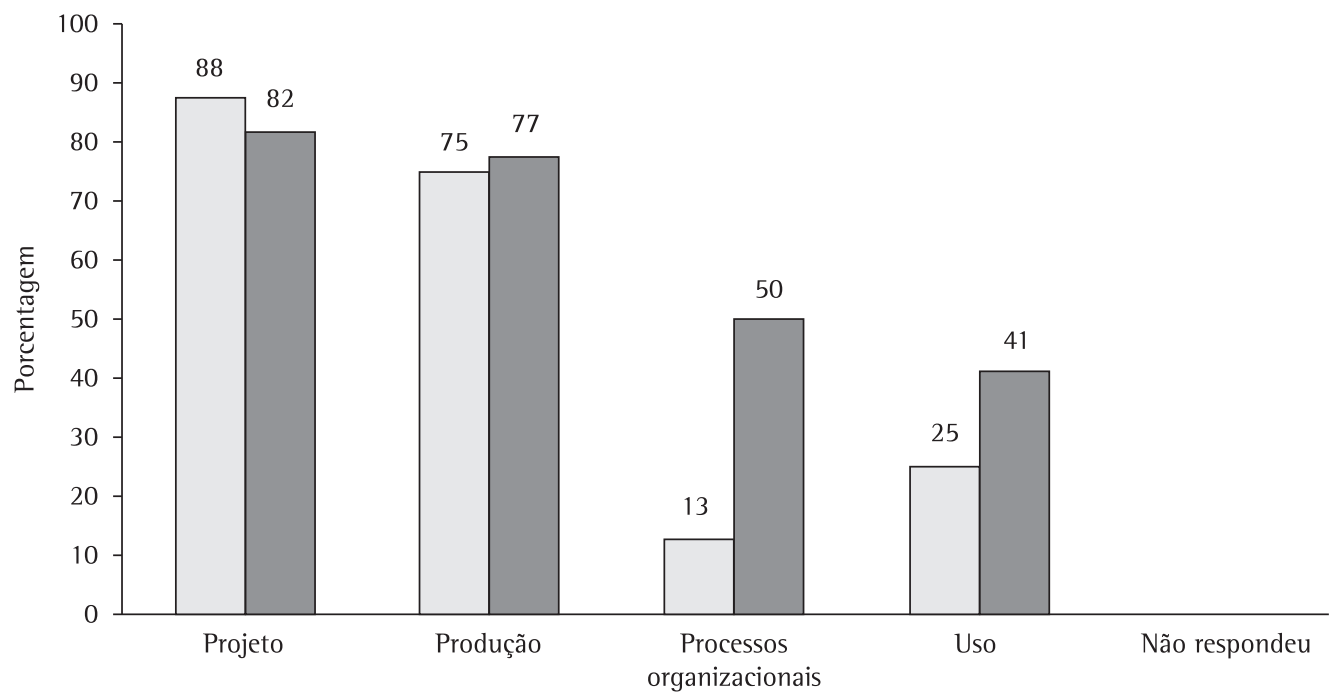

Tipo de modularidade utilizado

$\square$ Montadora

$\square$ Fornecedor

Figura 3. Tipo de modularidade que a empresa aplica ( $n=8$ montadoras e 22 fornecedores). Fonte: elaborado pelos autores.

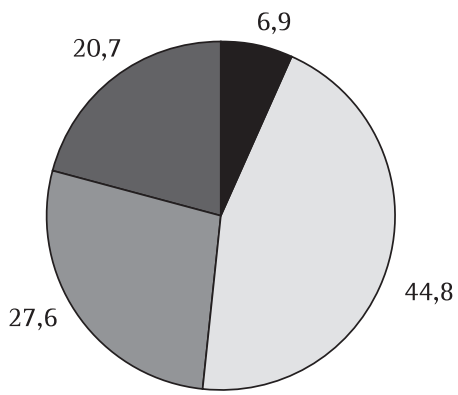

- Antes de $1990 \quad \square$ Entre 1990 a 1999

$\square$ Entre 2000 a $2009 \square$ Não respondeu

Figura 4. Período de implantação da modularidade ( $\mathrm{n}=30$; indicação em porcentagem. Fonte: elaborado pelos autores.

adotar a estratégia modular utilizando uma escala de 0 a 4 (0 - discordo totalmente, 1 - discordo parcialmente, 2 - não concordo nem discordo, 3 - concordo parcialmente e 4 - concordo totalmente). Verificou-se que, em relação às 8 montadoras, essas indicaram como:

- Concordo parcialmente e concordo totalmente: reduzir custos de fabricação pelo fato de os módulos poderem ser fabricados de forma independente, conforme estabelece Veloso e Fixon (2001) e Gu e Sosale (1999); aumentar a flexibilidade da produção, sendo este benefício citado por outras publicações (CONNOLLY, 2007; LAU et al., 2007; FREDRIKSSON, 2006b; HEILALA; VOHO, 2001; SANCHEZ; COLLINS, 2001; HOEK; WEKEN, 1998).

Sete empresas indicaram como:

- Concordo totalmente: reduzir o tempo de montagem, sendo este benefício relacionado à modularidade de produção bastante citado (DORAN, 2002; VELOSO; FIXSON, 2001; HOEK; WEKEN, 1998; PIRES, 1998; COLLINS et al., 1997);

- Concordo parcialmente e concordo totalmente: a busca de reduzir tempo de projeto, corroborando outras publicações (ARNHEITER; HARREN, 2005; SANCHEZ; COLLINS, 2001; VELOSO; FIXSON, 2001; GU; SOSALE, 1999).

Deste modo, sobre as montadoras que participaram do estudo verifica-se que os primeiros motivos para aplicar a modularidade estão associados àqueles citados na literatura. Além disso, as três primeiras razões podem ser classificadas como benefícios da modularidade de produção, enquanto que a quarta está mais relacionada com a modularidade de projeto.

Entretanto, algumas empresas assinalaram a opção discordo parcialmente para dois benefícios muito citados: aumentar a variedade de produtos (ORSATO; WELLS, 2007; RANKY, 2007; MOECKEL et al., 2006), por 3 montadoras, e reduzir a complexidade do produto (PANDREMENOS et al., 2009; VELOSO; FIXSON, 2001), por duas montadoras, sendo que para essas empresas esses não eram o foco da implantação que ajudassem na customização do produto. Aparentemente, o foco no setor automobilístico não está relacionado a facilitar a customização do produto ao cliente (apenas 4 empresas consideram essa possibilidade) mas há uma maior preocupação com reduzir os custos e aumentar a agilidade para melhor atender às variações de demanda.

Para os fornecedores, os motivos mais citados são (Figura 5): exigência da montadora e/ou do fornecedor de primeiro nível, no caso em que a empresa é um 


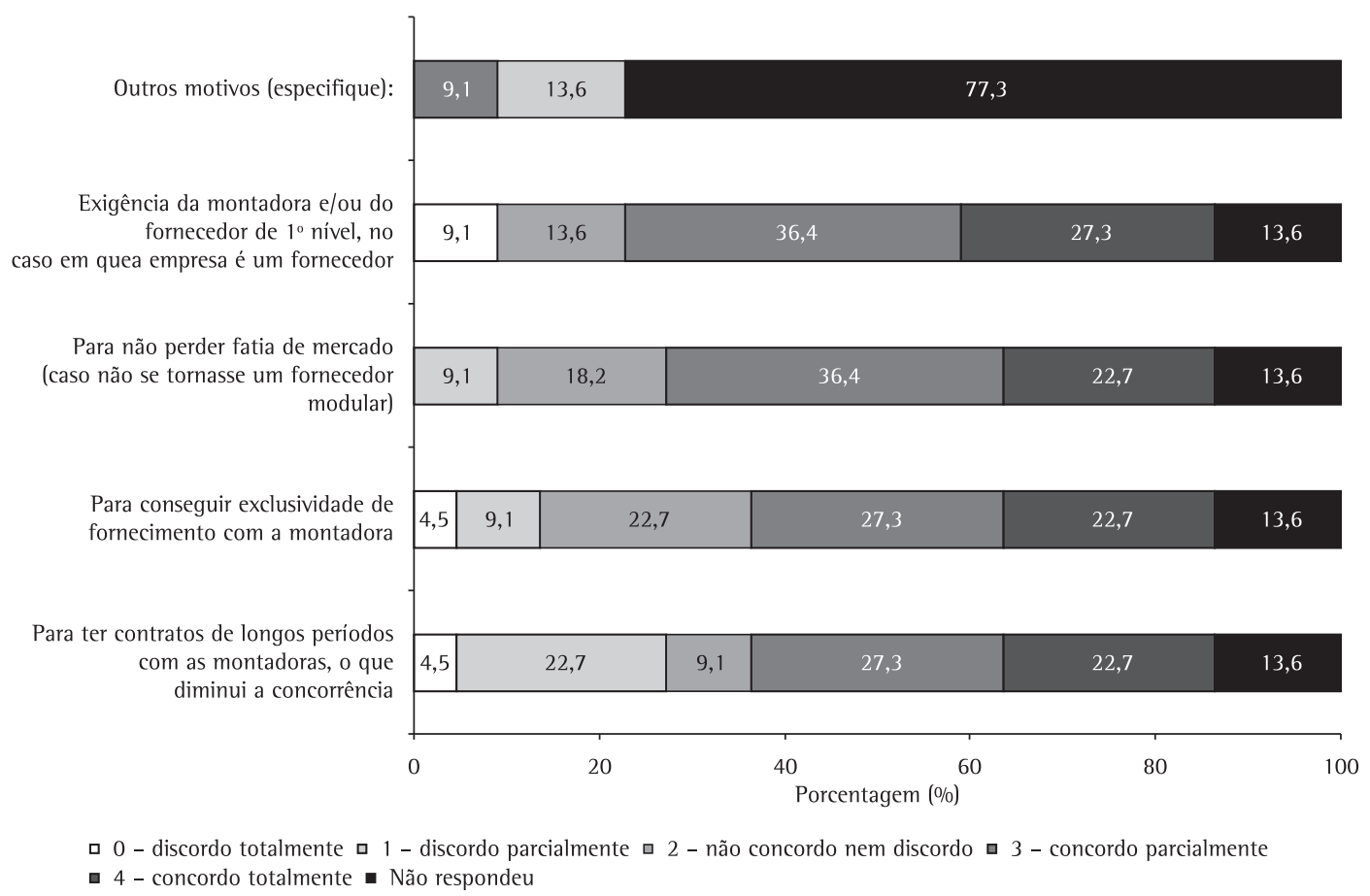

Figura 5. Motivos que levaram os fornecedores a adotar a modularidade ( $n=22$ empresas) Fonte: elaborado pelos autores.

fornecedor (também apontado por DORAN, 2002) e para não perder fatia de mercado (caso não se tornasse um fornecedor modular), defendido por Arnheiter e Harren (2005). Também se verificou que parte dos fornecedores (mais de 27\%) discordam totalmente ou discordam parcialmente de terem iniciado o uso da modularidade buscando contratos de longo prazo com as montadoras, como destacam várias publicações (ARNHEITER; HARREN, 2005; PIRES, 2002; COLLINS et al., 1997). Esses resultados indicam que, para a maioria dos fornecedores que responderam o questionário, a aplicação da modularidade ou é imposta pelo cliente (montadora) diretamente ou pelo mercado, indiretamente. Entretanto, alguns fornecedores citaram como outros motivos: melhorar a qualidade do produto, reduzir falhas de montagens ou agregar maior valor ao produto da empresa, indicando benefícios internos importantes.

As dificuldades mais citadas de aplicação da modularidade pelas 8 montadoras (concordo parcialmente mais concordo totalmente) foram:

- Encontrar fornecedores capacitados para fabricarem os módulos (6 empresas), dificuldade também apontada por Arnheiter e Harren (2005);

- Mudar a cadeia de suprimentos tradicional para a modular (4 empresas); também mencionada em outras publicações (DORAN, 2005; HOEK; WEKEN, 1998); e
- Pode limitar o projeto dos módulos à capacidade atual dos fornecedores em fabricá-los (4 empresas), convergente com Sanchez e Collins (2001).

Observa-se então que as principais dificuldades estão relacionadas à seleção dos fornecedores e organização da cadeia de suprimentos, o que pode significar um crescente interesse das empresas na transferência dos custos fixos para seus fornecedores. A maioria das montadoras também indicou como discorda totalmente ou discorda parcialmente as seguintes dificuldades:

- Reduz o desempenho do produto por usar módulos "genéricos" (ARNHEITER; HARREN, 2006; YIGIT et al., 2002); aumenta o risco da linha de montagem parar se houver problemas de entrega ou de qualidade (FREDRIKSSON, 2006a, c; LARSSON, 2002) - cada uma indicada por 6 das 8 empresas; e

- Realizar alteração organizacional para atender a estratégia modular (DORAN, 2005; CAMUFFO, 2000) e definir o método de modularidade a ser aplicado no produto (DORAN, 2005; ASAN et al., 2004; GADDE; JELLBO, 2002) - cada uma indicada por 5 empresas.

Esses resultados podem ter ocorrido pelo fato de os módulos não serem muito genéricos na indústria automobilística brasileira e por a maior parte da aplicação ser realizada em novas plantas das montadoras. Isso minimizaria as alterações organizacionais, pois a fábrica seria construída já considerando esses aspectos na aplicação da 
modularidade. Além disso, a dificuldade: aumenta o risco da linha de montagem parar se houver problemas de entrega ou de qualidade, indicado por Fredriksson (2006a, c), pode ter sido pouco citada porque esse aspecto pode ser avaliado e minimizado com maior rigor na escolha dos fornecedores e ser especificado em contrato. Sobre a dificuldade de definição do método de modularidade a ser aplicado no produto, diferentemente do que Asan et al. (2004) e Gadde e Jellbo (2002) indicaram, este problema não tem se destacado como dificuldade para a maioria das montadoras que participaram do estudo.

Quatro empresas também discordam da dificuldade risco de perda de controle de alguns projetos, pelos módulos serem projetados separadamente (destacado por ARNHEITER; HARREN, 2005), provavelmente por manterem algum controle ou coprojeto com o fornecedor, para evitar perda de know-how. Tal resultado está conforme com o que Mello e Marx (2007) indicaram ocorreu com a VW.
Em relação aos fornecedores, as principais dificuldades citadas como concordo parcialmente ou concordo totalmente são (Figura 6):

- Ter operações flexíveis à demanda (em mais de $77 \%$ das empresas), também mencionada por Fredriksson (2006a) e Doran (2003);

- Desenvolver habilidade de entregar módulos na linha de produção da montadora em mais de 68\% das empresas, conforme indicado por Doran (2004);

- Aumenta a dependência da empresa das decisões das montadoras em mais de 63\% das empresas, alinhado a outros estudos (HOLMES, 2004; FRIGANT; LUNG, 2002; HOEK; WEKEN, 1998); e

- Capacitar-se para fabricar os módulos (em mais de 59\% das empresas), também apontado pela literatura (ARNHEITER; HARREN, 2005; DORAN, 2002; COLLINS et al., 1997).

Verifica-se no presente estudo que a modularidade parece aumentar a dependência da maioria dos fornecedores investigados em relação às montadoras, pois eles serão afetados pela variação de volume e

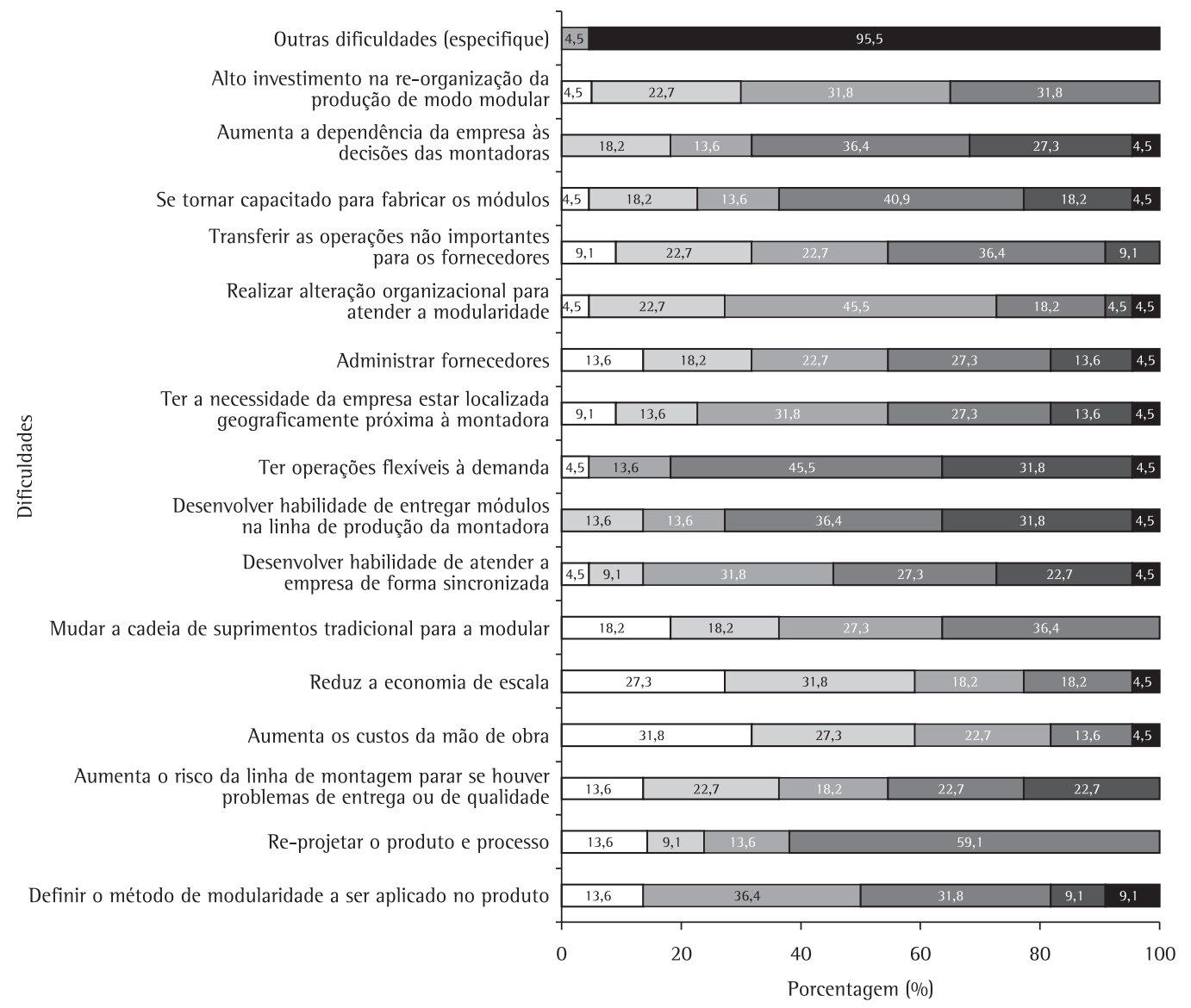

ㅁ 0 - discordo totalmente ㅁ 1 - discordo parcialmente ㅁ 2 - não concordo nem discordo $\square 3$ - concordo parcialmente

- 4 - concordo totalmente - Não respondeu

Figura 6. Principais dificuldades na aplicação da modularidade pelos fornecedores ( $\mathrm{n}=22$ empresas). Fonte: elaborado pelos autores 
de tempo de entrega dos módulos. Além disso, uma das empresas citou como outras dificuldades, a necessidade de a empresa desenvolver fornecedores de $3^{\circ}$ nível indicados pela montadora, o que reforça esta dependência.

Entretanto, algumas contradições com as dificuldades citadas na literatura também foram encontradas. Quase 60\% dos fornecedores indicaram como discordo totalmente ou discordo parcialmente as seguintes dificuldades:

- Aumenta os custos da mão de obra; e

- Reduz a economia de escala.

Esses resultados podem indicar que a transferência da atividade de fabricação e montagem dos módulos para o fornecedor não tem aumentado os custos da mão de obra nesses fornecedores, contrariando a indicação de Arnheiter e Harren (2005). Também verificou-se que, diferentemente do indicado por Fredriksson (2006b), a fabricação de módulos não tem reduzido a economia de escala, provavelmente por ser limitada às opções de cada modelo de módulo produzido. Isto pode ser explicado pelo fato de que não existe uma forte customização deste produto no Brasil. Além disso, segundo Salerno (2001), existem algumas indicações na literatura de que os fornecedores centralizam a produção dos módulos em suas fábricas e só fazem a montagem final dos módulos nos condomínios, para reduzir o investimento e ter escala de produção.

Em relação às dificuldades mudar a cadeia de suprimentos tradicional para a modular (DORAN, 2005; HOEK; WEKEN, 1998) e realizar alteração organizacional para atender a modularidade (DORAN, 2005; CAMUFF0, 2000), 36\% dos fornecedores discordam da primeira dificuldade e a mesma quantidade concorda. Mais de 27\% discordam da segunda, pouco mais de $22 \%$ concordam e $45 \%$ dos fornecedores não concordam nem discordam. Estes dados indicam que estas duas dificuldades podem não estar diretamente relacionadas com a modularidade e sim com o nível de organização da empresa e de sua cadeia de suprimentos durante a implantação da modularidade.

Sobre quais estratégias são utilizadas para realizar a modularidade de produto (Figura 7), verificou-se que mais de $96 \%$ das empresas que adotam a modularidade de projeto e/ou de uso (26 empresas) utilizam estratégias do produto, as quais consideram as funções do produto ou a estrutura do produto para a definição dos módulos. Cabe ressaltar que a Figura 7 refere-se a uma questão na qual se poderia assinalar mais de uma alternativa. Por esta razão a somatória de seus resultados superam 100\%. Apenas em pouco mais de 46\% das empresas também são utilizadas as estratégias de mercado. Desse modo, a segmentação do mercado não parece ser o principal aspecto na definição dos módulos, o que está de acordo com os motivos da aplicação já apresentados neste trabalho. 0 objetivo das montadoras é a redução de tempo de projeto, montagem, de custos, com o aumento de flexibilidade de produção, o que a estratégia do produto pode ajudar a atingir, conforme já discutido nos motivos de aplicação. Uma empresa citou na opção outras bases, que considera o know-how do fornecedor na definição dos módulos, o que reforça a dificuldade pode limitar o projeto dos módulos à capacidade atual dos fornecedores de fabricá-los já citada anteriormente.

$\mathrm{Na}$ Figura 8 verifica-se com mais detalhes como foi a definição dos módulos dos veículos, independentemente do tipo de modularidade utilizado.

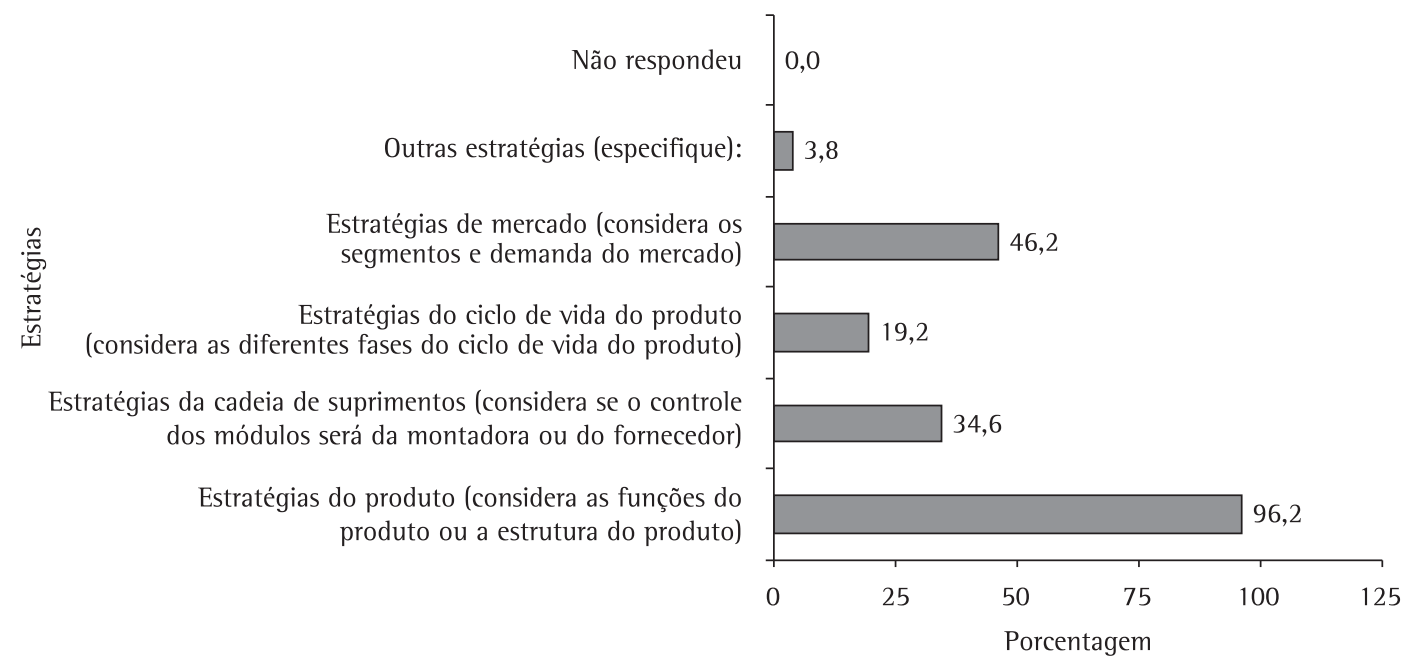

Figura 7. Identificação do tipo de estratégia usada na modularidade ( $n=26$ empresas). Fonte: elaborado pelos autores. 


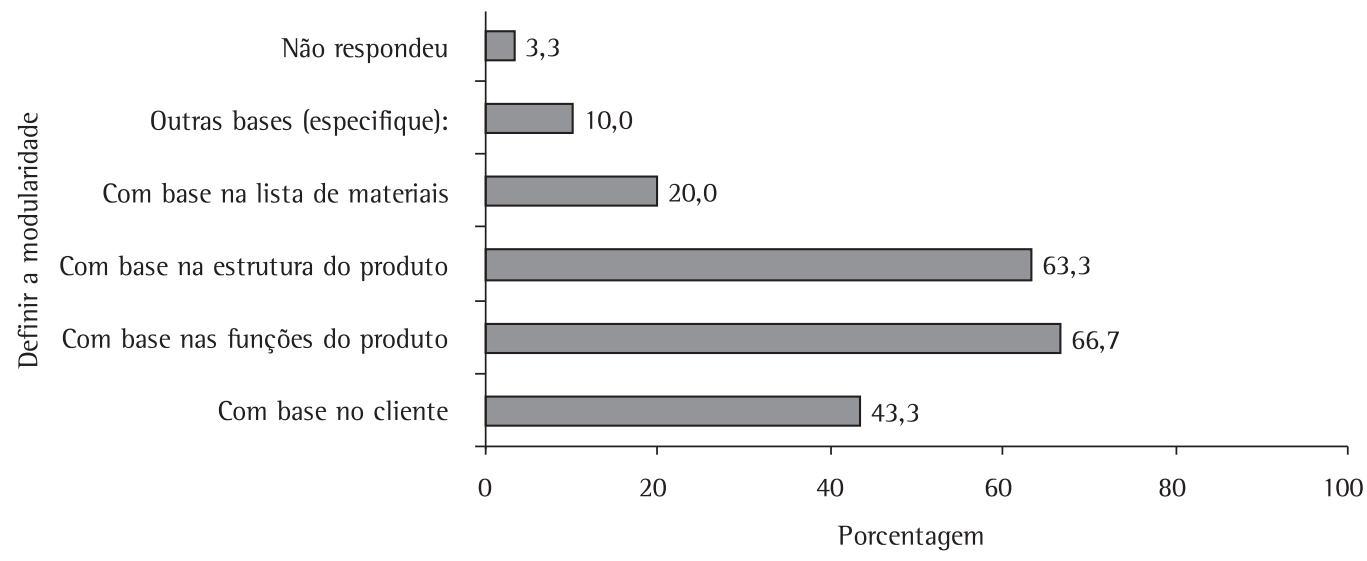

Figura 8. Identificação do tipo de abordagem usada na definição dos módulos ( $n=30$ empresas). Fonte: elaborado pelos autores.

Novamente, como no caso da Figura 7, destaca-se a definição baseada nas funções do produto (mais de $66 \%$, ou seja, 20 empresas) e com base na estrutura do produto (mais de 63\%, ou seja, 19 empresas). Em apenas pouco mais de 43\% das respostas é também considerado o cliente na definição dos módulos. Novamente, esta é uma indicação de que a customização do produto para o cliente não é uma prioridade dessas empresas, apesar da definição do módulo por funções do produto ser uma abordagem que favorece a customização. 0 uso das funções do produto para definir os módulos está presente em diversas publicações (SHIBATA et al., 2008; CONNOLLY, 2007; GADDE; JELLBO, 2002; DAHMUS et al., 2001).

A Figura 9 ilustra a existência de relações entre os diferentes tipos de modularidade, respondida por 25 das 26 empresas que utilizam mais de um tipo. Verifica-se, como esperado, que para quase $54 \%$ das empresas existe uma relação entre os diferentes tipos de modularidade, similar ao estabelecido por outros estudos (CAUCHICK MIGUEL; PIRES, 2006; FREDRIKSSON 2006b; PERSSON, 2006; ARNHEITER; HARREN, 2005). Entretanto, o que surpreendeu foi que mais de $42 \%$ das respostas indicaram que esta relação não existia. No entanto, essas respostas devem ser analisadas caso a caso, com mais detalhes em estudos futuros.

Para verificar se a aplicação da modularidade alterou as relações entre as empresas na cadeia de suprimentos utilizou-se a mesma escala de 0 a 4 já apresentada. Para 7 das 8 montadoras as principais alterações citadas como 3 - concordo parcialmente e 4 - concordo totalmente foram:

- Ocorreu a transferência, da montadora para o fornecedor, da atividade de submontagem dos módulos, em concordância com diversas publicações (MELLO; MARX, 2007; ORSATO; WELLS, 2007; FREDRIKSSON, 2006a; VELOSO; FIXSON, 2001; SALERNO et al., 1998); e
- Ocorreu a transferência, da montadora para o fornecedor, da atividade de fazer o projeto do módulo, conforme os trabalhos de Mello e Marx (2007), Fredriksson (2006a) e Salerno (2001).

Assim, verifica-se que a maioria das montadoras que participaram do estudo tem terceirizado parte das atividades de montagem e de projeto dos módulos para o fornecedor de primeiro nível, o que pode indicar uma política de redução de custos fixos por desverticalização das atividades das montadoras.

Em outros aspectos, a maioria das montadoras analisadas tem sido mais conservadora: 4 não têm transferido a atividade de gestão da cadeia de suprimentos para o fornecedor de primeiro nível, diferentemente do que indica Doran et al. (2007) no Reino Unido, mas, coerente com os resultados empíricos de Salerno (2001) e Salerno et al. (2009) e Salemo e De Negri (2005).

Em relação aos fornecedores, mais de 63\% indicaram que ocorreu transferência de atividades secundárias da sua empresa para o seu fornecedor (Figura 10). Esta é uma recomendação identificada em vários trabalhos de Doran $(2005,2004,2003)$ e Doran et al. (2007), enfatizando que os fornecedores podem focar mais especificamente nas atividades-chave relacionadas com os módulos que eles fornecem.

Também na Figura 10 pode-se verificar que em mais de 53\% das respostas existiu o fornecimento de know-how da sua empresa (fornecedor) para os seus fornecedores desenvolverem e/ou produzirem os submódulos ou componentes, indicando que a modularidade gera uma migração do conhecimento e de atividades na cadeia de suprimentos que vai além da montadora ao fornecedor de $1^{\circ}$ nível, atingindo outros níveis da cadeia. Entretanto, essa afirmação ainda necessita de maior investigação, que está além do escopo do presente trabalho. 
Sobre se existiu o fornecimento de apoio financeiro da sua empresa para o seu fornecedor desenvolver e ou produzir os submódulos ou componentes (destacado por DORAN, 2005), verificou-se que mais de 63\% dos fornecedores indicaram que discorda totalmente ou parcialmente, mostrando que é raro este apoio entre essas empresas.

Os benefícios da modularidade foram indicados pelas empresas utilizando uma escala de 0 a 4 , diferentemente das questões anteriores: 0 - não houve benefícios, 1 - poucos benefícios, 2 - benefícios satisfatórios, 3 - bons benefícios e 4 - excelentes benefícios, sendo considerados na análise as indicações de bons benefícios ou excelentes benefícios.

Em relação às montadoras, os benefícios mais citados como bons benefícios somados a excelentes

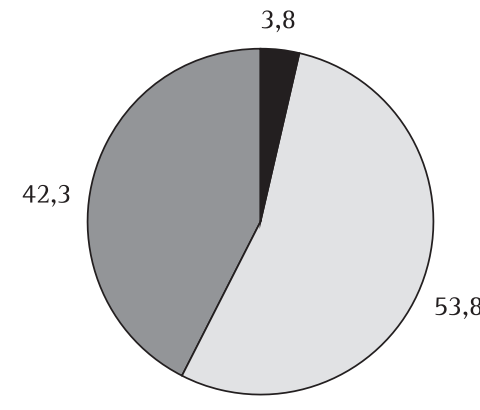

$\square \operatorname{Sim} \square$ Não $\square$ Não respondeu

Figura 9. Verificar se existe relação entre os diferentes tipos de modularidade ( $\mathrm{n}=26$ empresas). Fonte: elaborado pelos autores.

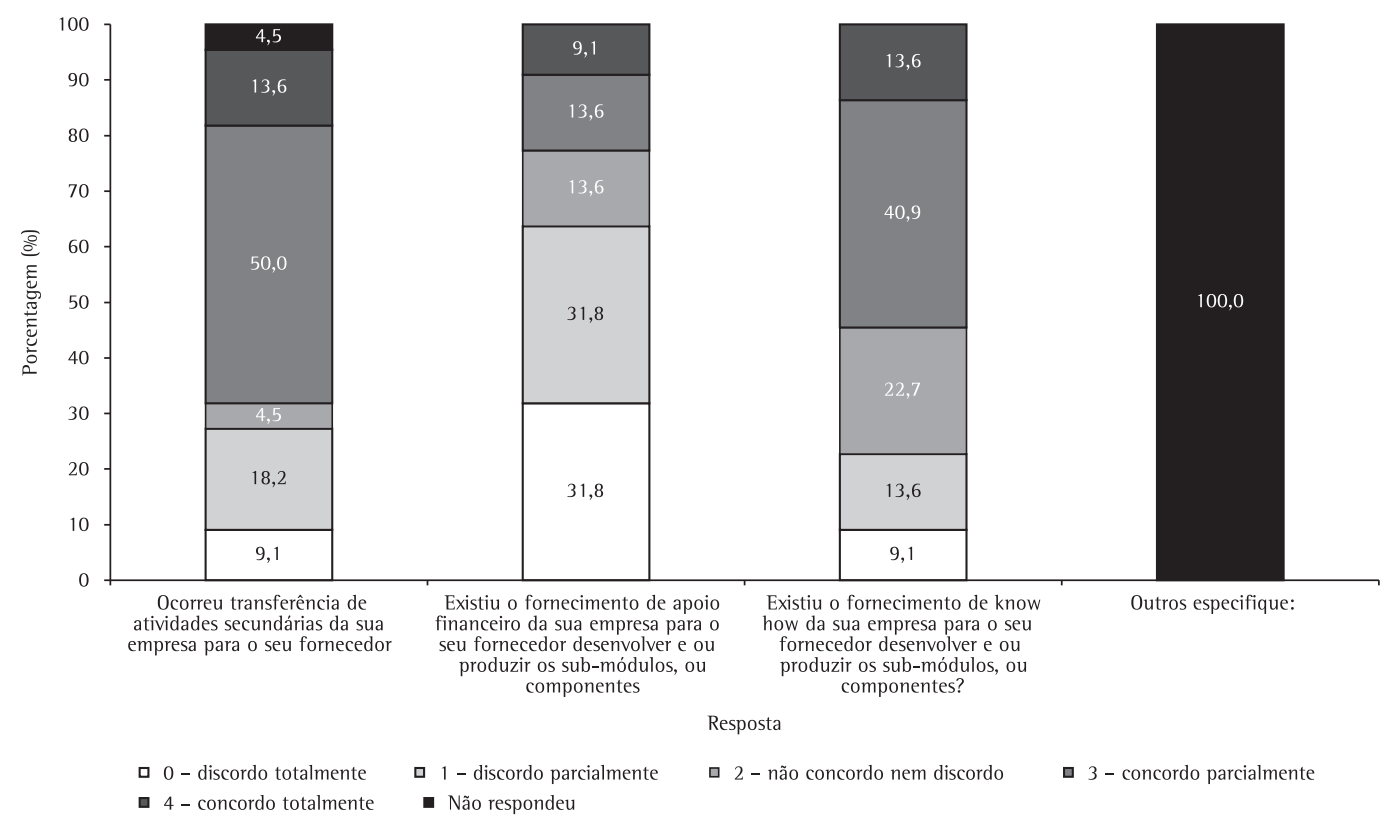

Figura 10. Alterações na cadeia de suprimentos que a modularidade trouxe em relação aos fornecedores com seus fornecedores ( $n=22$ empresas). Fonte: elaborado pelos autores.

benefícios (8 montadoras) foram: aumentou a parceria entre a montadora e o fornecedor pela participação dos fornecedores no desenvolvimento de novos produtos com a montadora, sugerindo um aumento dos coprojetos, o que pode ou não estar relacionado com uma estratégia de inovação aberta ou apenas uma redução de custos. Silva e Rozenfeld (2007) também identificaram essa parceria na VW no Brasil. Além desses benefícios, 7 das 8 montadoras também citaram:

- Ajudou no desenvolvimento de novos produtos por projetar alguns novos módulos, conforme Gu e Sosale (1999);

- Melhorou a confiabilidade do produto (apontado por ARNHEITER; HARREN, 2006; CEPOLINA; MICHELINI, 2003);

- Facilitou a manutenção do produto, destacado por vários autores (ARNHEITER; HARREN, 2006; MOECKEL et al., 2006; AREND et al., 2005; ZHANG et al., 2002; GU; SOSALE 1999);

- Reduziu o tempo de fabricação por se poder fabricar os módulos de forma independente (citado por VELOSO; FIXSON, 2001; GU; SOSALE 1999);

- Reduziu o tempo de montagem por se poder montar os módulos de forma independente (conforme destacam FREDRIKSSON, 2006b; DORAN, 2002; HOEK; WEKEN, 1998);

- Reduziu o custo de fabricação, mencionado por Veloso e Fixson (2001), sendo este benefício também relacionado à terceirização de alguns módulos para o fornecedor; 
- Reduziu a mão de obra direta na montadora, citado por diversas publicações (ARNHEITER; HARREN, 2005; DORAN, 2002; PIRES, 2002; COLLINS et al., 1997); e

- Possibilitou o envolvimento de fornecedores no processo de fabricação da montadora, conforme algumas referências (FRIGANT; LUNG, 2002; HOEK; WEKEN, 1998).

Assim sendo, verifica-se que parte desses benefícios são gerados pela terceirização de algumas atividades da montadora para o fornecedor, como a fabricação de alguns módulos. Além disso, as razões para a aplicação da modularidade têm sido satisfeitas diretamente ou indiretamente por estes benefícios, como redução dos custos de fabricação e do tempo de montagem e de projeto.

Entretanto, alguns benefícios que a literatura indica podem ocorrer ou não, conforme a empresa, tais como: reduziu a complexidade do produto (destacado por PANDREMENOS et al., 2009; VELOSO; FIXSON, 2001) e reduziu os custos de projeto por se poder projetar os módulos de forma independente, conforme Veloso e Fixson (2001). Para 3 montadoras esses benefícios não ocorreram ou apresentaram resultados não satisfatórios. Infelizmente não é possivel verificar as causas desses resultados, sendo necessário realizar uma investigação em maior profundidade, considerando esse foco específico, nas 8 montadoras.

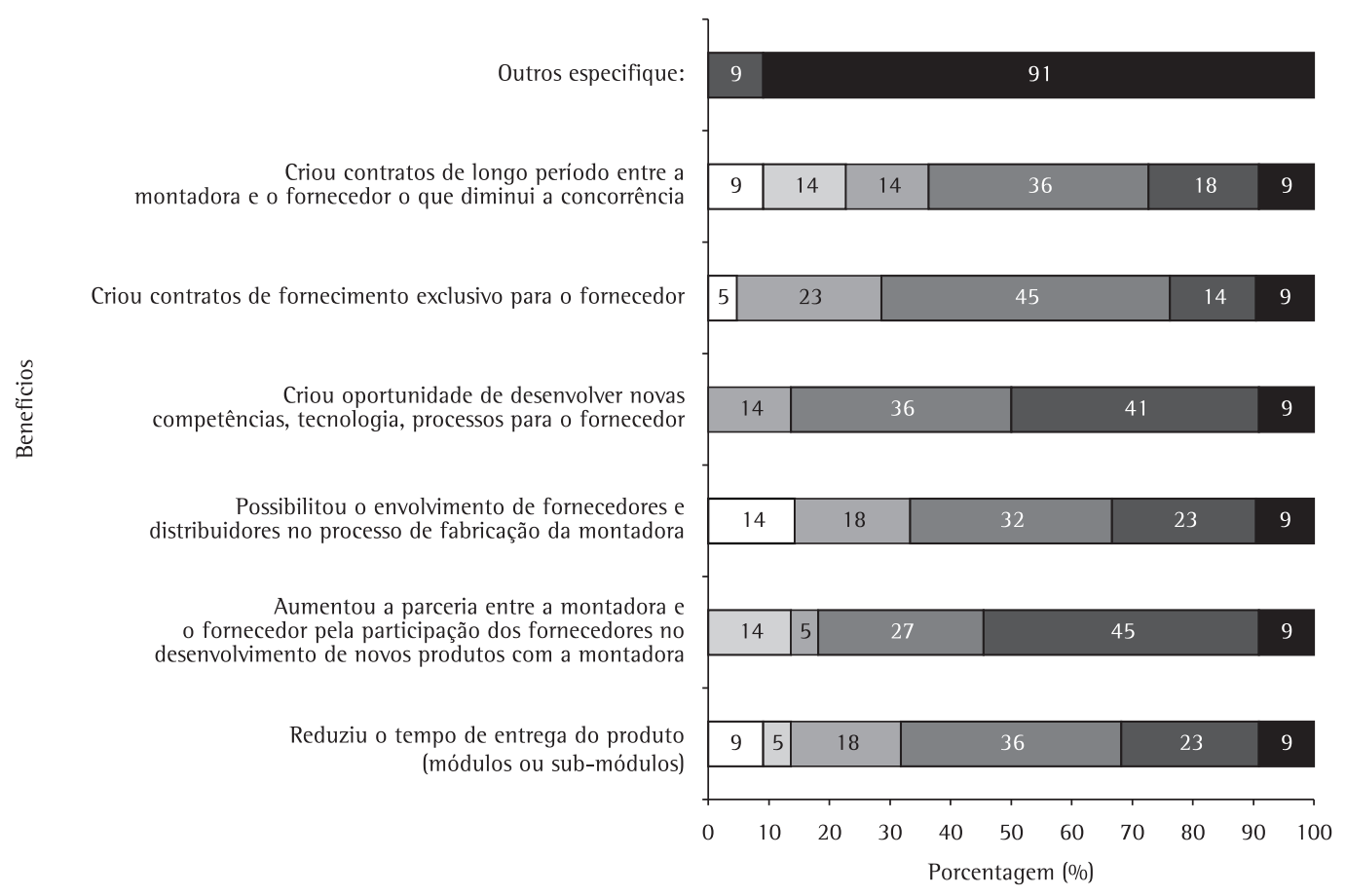

0 - discordo totalmente $\square 1$ - discordo parcialmente $\square 2$ - não concordo nem discordo $\square 3$ - concordo parcialmente - 4 - concordo totalmente - Não respondeu

Figura 11. Benefícios que a modularidade trouxe para os fornecedores ( $\mathrm{n}=22$ empresas). Fonte: elaborado pelos autores

Em relação aos fornecedores, os mais citados como bons benefícios somados a excelentes benefícios foram (Figura 11):

- Criou oportunidade de desenvolver novas competências, tecnologia, processos para o fornecedor (em 77\% das empresas), apontado pela literatura (PIRES, 1998; COLLINS et al., 1997);

- Aumentou a parceria entre a montadora e o fornecedor pela participação dos fornecedores no desenvolvimento de novos produtos com a montadora (em $72 \%$ das empresas). Este benefício também é apontado pelas montadoras, o que indica que esta parceria está ocorrendo e é visível tanto para o cliente (montadora) como para os fornecedores; e

- Criou contratos de fornecimento exclusivo para o fornecedor (em 59\% das empresas) o que é destacado também em outras publicações (TOLED0 et al., 2003; FRIGANT; LUNG, 2002; PIRES, 1998).

Portanto, os principais benefícios para o fornecedor são o aumento da parceria com os clientes e a possibilidade de desenvolver novas competências para aplicar a modularidade, além de, em alguns casos, conseguir exclusividade de fornecimento dos módulos que produz. Esses podem ser considerados benefícios estratégicos para a empresa e, conforme o caso, podem justificar as dificuldades a superar para a aplicação da modularidade.

. 
Buscando verificar se os 9 fornecedores que indicaram que não existem relações entre os diferentes tipos de modularidade apresentam resultados diferentes dos 10 fornecedores que afirmam que essa relação existe, fez-se uma análise sobre as dificuldades de aplicação encontradas em cada grupo. As principais dificuldades de aplicação apontadas pelos 9 fornecedores foram: desenvolver habilidade de entregar módulos na linha de produção da montadora (8 das 9 empresas) e ter operações flexíveis à demanda e administrar fornecedores ( 7 das 9 empresas). Numa proporção menor também aparecem as seguintes dificuldades: transferir as operações não importantes para os fornecedores e aumenta a dependência da empresa das decisões das montadoras ( 6 das 9 empresas). Esses resultados são similares à análise feita com os 22 fornecedores juntos, apresentada na Figura 6.

Para os 10 fornecedores para os quais os diferentes tipos de modularidade têm relação entre si, as dificuldades da aplicação dessa estratégia modular são mais dispersas. As principais dificuldades citadas foram: ter operações flexíveis à demanda (7 das 10 empresas); reprojetar produto e processo; aumenta o risco da linha de montagem parar se houver problemas de entrega ou de qualidade; capacitar-se a fabricar os módulos e aumenta a dependência da empresa das decisões das montadoras ( 6 das 10 empresas). Verifica-se assim que as empresas que indicaram a existência de relações entre os diferentes tipos de modularidade indicaram mais dificuldades relacionadas com a aplicação da modularidade quando comparadas com as empresas que indicaram não existir essa relação.

Como apresentado na Figura 3, a maior parte das empresas adota mais de um tipo de modularidade. Assim, seria interessante investigar as empresas agrupadas pela diversidade de tipos de modularidade que aplicam. Entretanto, para as montadoras esta análise não é possível pois, como são apenas 8 empresas, a estratificação por tipos limita a análise.

Já com relação aos fornecedores essa análise é mais viável. No entanto, como a quantidade também não é grande (22), só foi possível verificar algumas indicações apresentadas na Tabela 1. Apesar das limitações desses resultados, verificou-se que uma empresa que utiliza mais de dois tipos de modularidade apresenta uma melhor distribuição dos benefícios, mas, como já citado, esses resultados são limitados em termos de generalização.

Em relação às dificuldades de aplicação da modularidade, quando analisado por quantidade de tipos de modularidade aplicados, os resultados foram inconclusivos, devido a uma grande dispersão das respostas.

Analisando-se separadamente as empresas que não adotam a modularidade de produção sobre as alterações realizadas na cadeia de suprimentos, um fato inesperado foi verificado. Em 2 montadoras e em 3 fornecedores (de um total de 5 fornecedores que se enquadram neste caso), ocorreu a transferência, da montadora para o fornecedor, da atividade de submontagem dos módulos, o que sugere que esta desverticalização da montadora pode ser independente do uso ou não da modularidade de produção. Uma possível explicação para esse resultado é que, antes de o conceito modularidade ser difundido e tornar-se algo comum nas empresas, as montadoras já adquiriam de terceiros componentes como bancos e outros subconjuntos, que hoje são considerados "módulos".

Nas duas montadoras que não usam a modularidade de produção também foi possível fazer essa análise dos benefícios da modularidade, indicando:

- Aumentou a flexibilidade da produção;

- Reduziu o tempo de fabricação por se poder fabricar os módulos de forma independente;

- Reduziu o tempo de montagem por se poder montar os módulos de forma independente;

Tabela 1. Benefícios da modularidade por número de tipos aplicados.

\begin{tabular}{|c|c|c|c|c|}
\hline $\begin{array}{l}\text { Total de tipos de modularidade aplicados } \\
\text { (1 de projeto; } 2 \text { de produção; } 3 \text { de processos } 4 \text { organizacionais; de uso) }\end{array}$ & 1 & 2 & 3 & 4 \\
\hline Reduziu o tempo de entrega do produto (módulos ou submódulos) & 50,0 & 54,5 & 60,0 & 75,0 \\
\hline $\begin{array}{l}\text { Aumentou a parceria entre a montadora e o fornecedor pela participação dos fornecedores no } \\
\text { desenvolvimento de novos produtos com a montadora }\end{array}$ & 50,0 & 81,8 & 80,0 & 50,0 \\
\hline $\begin{array}{l}\text { Possibilitou o envolvimento de fornecedores e distribuidores no processo de fabricação da } \\
\text { montadora }\end{array}$ & 100,0 & 45,5 & 60,0 & 50,0 \\
\hline $\begin{array}{l}\text { Criou oportunidade para o desenvolvimento de novas competências, tecnologias, processos } \\
\text { para o fornecedor }\end{array}$ & 100,0 & 81,8 & 60,0 & 75,0 \\
\hline Criou contratos de fornecimento exclusivo para o fornecedor & 50,0 & 54,5 & 60,0 & 75,0 \\
\hline $\begin{array}{l}\text { Criou contratos de longo período entre a montadora e o fornecedor, o que diminui a } \\
\text { concorrência }\end{array}$ & 50,0 & 45,5 & 60,0 & 75,0 \\
\hline Outros & 0,0 & 0,0 & 20,0 & 25,0 \\
\hline Total de empresas & 2 & 11 & 5 & 4 \\
\hline
\end{tabular}

Fonte: elaborado pelos autores 
Quadro 2. Síntese dos resultados.

\begin{tabular}{|c|c|c|}
\hline Aspecto mais citado & Montadora & Fornecedor \\
\hline $\begin{array}{l}\text { Experiência no uso da } \\
\text { modularidade }\end{array}$ & Maioria tem experiência no seu uso & Maioria tem experiência no seu uso \\
\hline Tipo de modularidade utilizado & Maioria utiliza mais de um tipo de modularidade & $\begin{array}{l}\text { Maioria utiliza mais de um tipo de } \\
\text { modularidade }\end{array}$ \\
\hline Motivos de aplicação & $\begin{array}{l}\text { Redução de custos e o aumento da agilidade no projeto e } \\
\text { na produção }\end{array}$ & Imposto pelos clientes \\
\hline Principais dificuldades & $\begin{array}{c}\text { Dificuldade de seleção dos fornecedores capacitados e } \\
\text { organização da cadeia de suprimentos }\end{array}$ & $\begin{array}{c}\text { Obrigação de capacitar-se para aplicar } \\
\text { esta abordagem }\end{array}$ \\
\hline Principais benefícios & $\begin{array}{l}\text { Terceirização de parte das atividades de montagens, } \\
\text { fabricação e de projeto para seus fornecedores (redução } \\
\text { de custos fixos; aumento da agilidade das empresas no } \\
\text { desenvolvimento de projetos e no aumento da flexibilidade } \\
\text { da produção) }\end{array}$ & $\begin{array}{l}\text { Aumento da parceria com os clientes } \\
\text { (participação em coprojeto) e, em alguns } \\
\text { casos, conquista da exclusividade de } \\
\text { fornecimento }\end{array}$ \\
\hline
\end{tabular}

Fonte: elaborado pelos autores.

- Reduziu o custo de fabricação;

- Reduziu os custos de montagem porque as submontagens dos módulos são feitas pelos fornecedores;

- Reduziu a mão de obra direta na montadora;

- Reduziu o tamanho da linha de montagem; e

- Aumentou a variedade de produtos pela troca de alguns módulos.

É provável que esses benefícios ocorram devido à combinação da adoção da modularidade de projeto com a terceirização da produção para os fornecedores, sugerindo que não são benefícios exclusivos da modularidade de produção. No entanto, essa relação causal não pode ser confirmada no presente trabalho.

Sobre as empresas que não utilizam a modularidade de projeto, nem a de uso, apenas 3 empresas se enquadram nesta situação (1 montadora e 2 fornecedores). Os resultados nesse caso não foram significativos para análise devido às limitações do questionário, pois para os fornecedores os benefícios indicados não são exclusivos da modularidade de projeto ou de uso.

0 Quadro 2 apresenta uma síntese dos resultados da pesquisa. A seguir serão apresentadas as principais conclusões deste estudo.

\section{Conclusões}

Primeiramente cabe ressaltar que o presente trabalho cumpriu seu objetivo: identificar empresas do setor automobilístico que utilizam a estratégia modular e analisar aspectos do seu uso. Verificou-se entre os benefícios da desverticalização de parte das atividades produtivas da montadora para o fornecedor, por exemplo, a redução dos custos de montagem, da mão de obra na montadora e do tamanho da linha de montagem, já que os fornecedores fazem as submontagens e são independentes da modularidade de produção, ao contrário do que era previsto, apesar de terem relação estreita com a literatura estudada.

Sobre os motivos de aplicação da modularidade, verificou-se que o foco, na indústria automobilística, não está na customização do produto para o cliente, mas sim na redução de custos e no aumento da agilidade dos setores de projeto e produção para melhor atender as variações de demanda.

Sobre as principais dificuldades do uso da modularidade observou-se que a transferência da atividade de fabricação e montagem dos módulos para o fornecedor não aumentou os custos da mão de obra dos fornecedores, contrariando indicações da literatura. No entanto, esse fato não foi quantificado e, sendo somente indicação, necessita de aprofundamento investigativo. Algumas das dificuldades citadas na literatura não foram confirmadas por pelo menos metade das montadoras analisadas, diferente do previsto. Essas dificuldades estão associadas a aspectos do produto (usar módulos "genéricos”), à linha de produção (riscos de parada por problemas de entrega) e a necessidades organizacionais (alterações para aplicar a modularidade e definição de como aplica-la).

Conclusivamente, esses resultados podem ter ocorrido em função de que:

- Os módulos realmente não são genéricos, sendo específicos para cada família de veículos;

- Os veículos são divididos em módulos que facilitam a montagem do produto; e

- Grande parte da aplicação da modularidade foi realizada em novas plantas, projetadas para recebê-la, o que minimizaria as alterações organizacionais.

Além disso, os fornecedores podem estar sendo selecionados buscando-se minimizar o risco de paradas da linha de montagem, assim como a consideração do arranjo em condomínios industriais.

Nos casos dos benefícios do uso da modularidade, conclui-se que esses não atingem uniformemente os diferentes níveis da cadeia de suprimentos, pois têm 
favorecido mais as montadoras, sendo associados à terceirização de parte das atividades de montagem, fabricação e de projeto para os fornecedores e à redução de custos fixos (não mensurados no presente trabalho). Para os fornecedores, a modularidade tem gerado benefícios que podem ser considerados estratégicos, como: o aumento da parceria com os clientes (participação em coprojeto) e, em alguns casos, conquista da exclusividade de fornecimento dos módulos.

Limitando-nos às empresas que participaram do levantamento, conclui-se que as montadoras são as mais favorecidas na aplicação da modularidade, pois apontaram mais benefícios e menos dificuldades. É importante destacar que as montadoras são o elo mais forte na cadeia de suprimentos automotiva, tema para continuidade da presente investigação, visando seu aprofundamento. Outra possibilidade de trabalho futuro é explorar as razões pelas quais algumas empresas indicaram que não existem relações entre os diferentes tipos de modularidade, um resultado não esperado.

Finalmente, cabe destacar que os resultados e respectiva análise são de caráter confirmatório. Esta é uma característica esperada para levantamentos tipo survey descritivo. Como já citado anteriormente, pretende-se dar continuidade à presente proposta, aprofundando os resultados por meio da condução de investigação específica nas unidades de análise com maior maturidade na aplicação da modularidade, possivelmente por meio da abordagem de múltiplos estudos de caso.

\section{Referências}

AREND, L. et al. Desenvolvimento e teste de uma semeadora-adubadora modular para pequenas propriedades rurais. Engenharia Agrícola, v. 25, n. 3, p. 801-808, 2005. http://dx.doi.org/10.1590/ S0100-69162005000300027

ARNHEITER, E. D.; HARREN, H. A typology to unleash the potential of modularity. Journal of Manufacturing Technology Management, v. 16, n. 7, p. 699-711, 2005. http://dx.doi.org/10.1108/17410380510619923

ARNHEITER, E. D.; HARREN, H. Quality management in a modular world. The TQM Magazine, v. 18, n. 1, p. 87-96, 2006. http://dx.doi. org/10.1108/09544780610637712

ASAN, U. et al. An integrated method for designing modular products. Journal of Manufacturing Technology management, v. 15, n. 1, p. 29-49, 2004. http://dx.doi. org/10.1108/09576060410512257

BALDWIN, C. Y.; CLARK K. B. Managing in the Age of Modularity. Harvard Business Review, 1997.

BALDWIN, C.Y.; CLARK K. B. Design Rules. Massachusetts: MIT Press, 2000.
BOYD, H. W. J.; WETFAll, R. Pesquisa mercadológica: texto e caso. Rio de Janeiro: Fundação Getúlio Vargas, 1964. v. 1.

CAMUFFO, A. Rolling out a World Car. Globalization, Outsourcing and Modularity in the Auto Industry. IMVP, 2000. Working Paper. Disponível em: <http:// www.imvpnet.org/publications.asp?txtKeywords=camuff oftSelMatchType=AND>. Acesso em 20 abr. 2009.

CAUCHICK MIGUEL, P. A.; PIRES, S. R. 1. A case study on modularity in product development and production within the auto industry. International Journal of Automotive Technology and Management, v. 6, n. 3, p. 315-330, 2006. http://dx.doi.org/10.1504/ IJATM.2006.012123

CEPOLINA, F.; MICHELINI, R. C. A family of co-robotic surgical set-ups. Industrial Robot: An International Journal, v. 30, n. 6, p. 564-574, 2003.

COLLINS, R. et al. Outsourcing in the automotive industry: from JIT to Modular Consortia. European Management Journal, v. 15, n. 5, p. 498-508, 1997. http://dx.doi. org/10.1016/S0263-2373(97)00030-3

CONNOLLY, C. Robots at the heart of Schubert packaging machinery lead to great flexibility. Industrial Robot: An International Journal, v. 34, n. 4, p. 277-280, 2007.

DAHMUS, J. B. et al. Modular product architecture. Design Studies, v. 22, n. 5, p. 409-424, 2001. http://dx.doi. org/10.1016/S0142-694X(01)00004-7

DIAS, A. V. C.; SALERNO, M. S. Descentralização das atividades de pesquisa, desenvolvimento e engenharia de empresas transnacionais: uma investigação a partir da perspective de subsidiárias automotivas. Gestão \& Produção, v. 16, n. 2, p. 187-199, 2009. http://dx.doi. org/10.1590/S0104-530X2009000200003

DORAN, D. et al. Supply chain modularisation: Cases from the French automobile industry. International Journal of Production Economics, v. 106, n. 1, p. 2-11, 2007. http://dx.doi.org/10.1016/j.ijpe.2006.04.006

DORAN, D. Manufacturing for synchronous supply: a case study of lkeda Hoover Ltd. Integrated Manufacturing Systems, v. 13, n. 1, p. 18-24, 2002. http://dx.doi. org/10.1108/09576060210411477

DORAN, D. Rethinking the supply chain: an automotive perspective. Supply Chain Management: An International Journal, v. 9, n. 1, p. 102-109, 2004. http://dx.doi. org/10.1108/13598540410517610

DORAN, D. Supply Chain Implications of Modularization. International Journal of Operations and Production Management, v. 23, n. 3, p. 316-326, 2003.

DORAN, D. Supplying on a modular basis: an examination of strategic issues. International Journal of Physical Distribution \& Logistics Management, v. 35, n. 9, p. 654-663, 2005. http://dx.doi. org/10.1108/09600030510632023

ELPHICK, P. Liberty: The Ships that Won the War. London: Chatham Publishing, 2006.

FORZA, C. Surveys research in operations management: a process-based perspective. International Journal of Operations \& Production Management, v. 22, n. 2, p. 152-194, 2002. http://dx.doi. org/10.1108/01443570210414310

FREDRIKSSON, P. Cooperation and conflict in modular production and supplier parks: the case of Volvo Cars' modular assembly system. International Journal 
of Automotive Technology and Management, v. 6, n. 3, p. 298-314, 2006a. http://dx.doi.org/10.1504/ IJATM.2006.012122

FREDRIKSSON, P. Mechanisms and rationales for the coordination of a modular assembly system: The case of Volvo Cars. International Journal of Operations \& Production Management, v. 26, n. 4, p. 350-370, 2006b. http://dx.doi.org/10.1108/01443570610650530

FREDRIKSSON, P. Operations and logistics issues in modular assembly processes: cases from the automotive sector. Journal of Manufacturing Technology Management, v. 17, n. 2, p. 168-186, 2006c. http://dx.doi. org/10.1108/17410380610642250

FRIGANT, V.; LUNG, Y. Geografical proximity and supplying relationships in modular production. International Journal of Urban and Regional Research, v. 26, n. 4, p. 742-755, 2002. http://dx.doi. org/10.1111/1468-2427.00415

GADDE, L. E.; JELLBO 0. System sourcing - opportunities and problems. European Journal of Purchasing \& Supply Management, v. 8, n. 1, p. 43-51, 2002. http://dx.doi. org/10.1016/S0969-7012(01)00013-2

GU, P.; SOSALE, S. Product modularization for life cycle engineering. Robotics and Computer Integrated Manufacturing, v. 15, n. 5, p. 387-401, 1999. http:// dx.doi.org/10.1016/S0736-5845(99)00049-6

HEILALA, J.; VOHO, P. Modular reconfigurable flexible final assembly systems. Assembly Automation, v. 21, n. 1, p. 20-28, 2001. http://dx.doi. org/10.1108/01445150110381646

HOEK, R. I. V.; WEKEN, H. A. M. The Impact of Modular Production on the Dynamics of Supply Chains. The International Journal of Logistics Management, v. 9, n. 2, p. 35-50, 1998. http://dx.doi. org/10.1108/09574099810805825

HOLMES, J. Re-scaling collective bargaining: union responses to restructuring in the North American auto industry. Geoforum, v. 35, n. 1, p. 9-21, 2004. http://dx.doi. org/10.1016/j.geoforum.2003.06.001

LARSSON, A. The development and regional significance of the automotive industry: supplier parks in western Europe. International Journal of Urban and Regional Research, v. 26, n. 4, p. 767-784, 2002. http://dx.doi. org/10.1111/1468-2427.00417

LAU, A. K. W. et al. The impacts of product modularity on competitive capabilities and performance: An empirical study. International Journal of Production Economics, v. 105, n. 1, p. 1-20, 2007. http://dx.doi.org/10.1016/j. ijpe.2006.02.002

LEVIN, J. Estatística aplicada a ciências humanas. 2. ed. São Paulo: Harbra, 1987. 392 p.

MARCONI, M. D. A.; LAKATOS, E. M. Técnicas de pesquisa: planejamento e execução de pesquisas, amostragens e técnicas de pesquisas, elaboração, análise e interpretação de dados. 6. ed. 3. reimpr. São Paulo: Atlas, 2007.

MARX, R.; ZILBOVICIUS, M.; SALERNO, M. S. The modular consortium in a new VW truck plant in Brazil: new forms of assembler and supplier relationship. Integrated Manufacturing Systems, v. 8, n. 5, p. 292-298, 1997. http://dx.doi.org/10.1108/09576069710179742

MATTAR, F. N. Pesquisa de marketing: edição compacta. São Paulo: Atlas, 1996.
MELLO, A. M. D.; MARX, R. Innovative capacity maintenance by automakers in a product development outsourcing scenario: the case of VW in Brazil. International Journal of Automotive Technology and Management, v. 7, n. 2-3, p. 200-215, 2007. http://dx.doi.org/10.1504/ IJATM.2007.014975

MOECKEL, R. et al. Exploring adaptive locomotion with YaMoR, a novel autonomous modular robot with Bluetooth interface. Industrial Robot: An International Journal, v. 33, n. 4, p. 285-290, 2006.

MORRIS, D.; DONNELLY, T. Are there market limits to modularisation? International Journal of Automotive Technology and Management, v. 6 , n. 3 , p. 262-275, 2006. http://dx.doi.org/10.1504/ IJATM.2006.012120

OLIVEIRA, S. L. Tratado de metodologia científica: projetos de pesquisas, TGl, TCC, monografias, dissertações e teses. São Paulo: Pioneira, 1997.

ORSATO, R. J.; WELLS, P. U-turn: the rise and demise of the automobile industry. Journal of Cleaner Production, v. 15, n. 11-12, p. 994-1006, 2007. http://dx.doi. org/10.1016/j.jclepro.2006.05.019

PANDREMENOS, J. et al. Modularity concepts for the automotive industry: A critical review. CIRP Journal of Manufacturing Science and Technology, v. 1, n. 3, p. 148-152, 2009. http://dx.doi.org/10.1016/j. cirpj.2008.09.012

PERSSON, M. Effects of changing a module's interface: a case study in na automotive company. International Journal of Automotive Technology and Management v. 6, n. 3, p. 331-345, 2006. http://dx.doi.org/10.1504/ IJATM.2006.012124

PIRES, S. R. 1. Managerial implications of the modular consortium model in a Brazilian automotive plant. International Journal of Operations \& Production Management, v. 18, n. 3, p. 221-232, 1998. http:// dx.doi.org/10.1108/01443579810368290

PIRES, S. R. I. New productive systems in the automotive industry: the current situation of three innovative plants Brazil. Internal Journal of Automotive Technology and Management, v. 2, n. 1, p. 46-62, 2002. http://dx.doi. org/10.1504/1JATM.2002.000056

RACHID, A. et al. Organização do trabalho na cadeia de suprimento: os casos de uma planta modular e uma tradicional na indústria automobilística. Produção, v. 16, n. 2, p. 189-202, 2006.

RANKY, G. N. Mobile robot sensor and networking design to enable cooperative behavior. Industrial Robot: $A n$ International Journal, v. 34, n. 1, p. 21-25, 2007.

SAKO, M.; MURRAY, F. Modules in Design, Production and Use: implications for the global automotive industry. Cambridge: IMVP. 1999.

SALERNO, M. S.; DE NEGRI, J. A. Inovação, estratégias competitivas e inserção internacional das firmas da indústria brasileira. Parcerias Estratégicas, n. 20, parte 4 p. 1309-1333, 2005.

SALERNO, M. S. et al. The importance of locally commanded design for the consolidation of local supply chain: the concept of design headquarters. International Journal of Manufacturing Technology and Management, v. 16, n. 4, p. 361-376, 2009. http://dx.doi.org/10.1504/ IJMTM.2009.023753 
SALERNO, M. S. et al. Modularity ten years after: an evaluation of the Brazilian experience. International Journal of Automotive Technology and Management, v. 8 , n. 4, p. 373-381, 2008. http://dx.doi.org/10.1504/ IJATM.2008.020309

SALERNO, M. S. et al. Mudanças e persistências no padrão de relações entre montadoras e autopeças no Brasil. Revista de Administração, v. 33, n. 3, p. 16-28, 1998.

SALERNO, M. S. The characteristics and the role of modularity in the automotive business. International Journal of Automotive Technology and Management, v. 1, n. 1, p. 92-107, 2001. http://dx.doi.org/10.1504/ IJATM.2001.000029

SANCHEZ, R.; COLLINS, R. P. Competing - and Learning - in Modular Markets. Long Range Planning, v. 34, n. 6, p. 645-667, 2001. http://dx.doi.org/10.1016/ S0024-6301(01)00099-1

SCAVARDA, L. F. et al. Comparação entre as tendências e estratégias da indústria automotiva no Brasil e na Europa. Gestão \& Produção, v. 12, n. 3, p. 361-375, 2005. http:// dx.doi.org/10.1590/S0104-530X2005000300007

SHIBATA, T. et al. Empirical analysis of evolution of product architecture Fanuc numerical controllers from 1962 to 1997. Research Policy, v. 34, n. 1, p. 13-31, 2008. http://dx.doi.org/10.1016/j.respol.2004.09.011

SILVA, S. L.; ROZENFELD, H. Model for mapping Knowledge Management in product development: a case study at a truck and bus manufacturer. International Journal of Automotive Technology and Management, v. 7, n. 2-3, p. 216-234, 2007. http://dx.doi.org/10.1504/ IJATM.2007.014976

TOLED0, J. C. et al. Participation of suppliers in product development process: the case of Fiat New Palio. Product: Management \& Development, v. 2, n. 1, p. 53-67, 2003.

VELOSO, F.; FIXSON, S. Make-Buy Decisions in the Auto Industry: New Perspectives on the Role of the Supplier as an Innovator. Technological Forecasting and Social Change, v. 67, n. 2-3, p. 239-257, 2001. http://dx.doi. org/10.1016/S0040-1625(00)00092-5

YlGIT, A. et al. Optimizing modular product design for reconfigurable manufacturing. Journal of Intelligent Manufacturing, v. 13, n. 4, p. 309-316, 2002. http:// dx.doi.org/10.1023/A:1016032714680

ZHANG, G. W. et al. Research on flexible transfer line shematic design using hierarchical process planning. Journal of Materials Processing Technology, v. 129, n. 1-3, p. 629-633, 2002. http://dx.doi.org/10.1016/ S0924-0136(02)00670-2

\section{Agradecimentos}

Os autores agradecem o apoio recebido da FAPESP (bolsa de pós-doutorado, processo: 2008/02695-8 e projeto de pesquisa processo 2007/02877-6), e ao CNPq (bolsa PQ). Os autores também agradecem Marco Antonio Domingues (pelo auxílio na localização dos endereços das empresas), Angelo Varandas Júnior e Edilson Alves Rodrigues (pela revisão do questionário), Marcos Carazatto Gimenez (por responder o questionário piloto) e às empresas que participaram do levantamento respondendo o questionário. Um dos autores tem vínculo com a Universidade Federal de Santa Catarina, o outro, com a Pontifícia Universidade Católica de Campinas, a essas instituições, também os nossos agradecimentos. Finalmente, os autores agradecem sinceramente aos avaliadores da Produção a contribuição na melhoria do trabalho.

\title{
Survey research on the application of modularity in the automotive industry in Brazil
}

\begin{abstract}
The purpose of this research is to identify automotive sector companies that use modular strategies and analyze aspects of its use. To this end, a survey research was carried out though a questionnaire sent to about 350 companies in the sector, with a response rate of nearly $14 \%$. Results showed that most companies adopt the modularity strategy and have some experience in its use. Concerning the difficulties experienced, the major problems faced by assemblers are related to finding capable suppliers in order to use the strategy. With regard to suppliers, the difficulties are related to fulfilling automotive assemblers' new demands to modular design and manufacturing. Regarding automotive assemblers, the main benefit of adopting modularity is linked to the outsourcing of some activities to suppliers, transferring fixed costs to them. Concerning suppliers, the main benefit is the partnership increase with customers, such as exclusive supply and the development of new organizational competencies.
\end{abstract}

Keywords

Modularity. Modular design. Modular production. Automotive industry. 